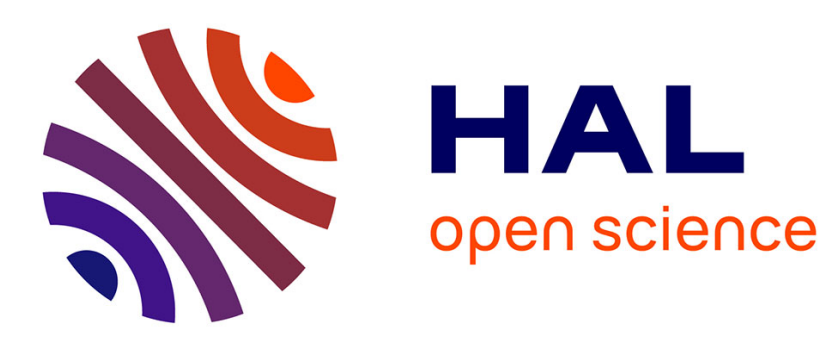

\title{
Characterizing hydraulic properties of filter material of a vertical flow constructed wetland
}

\author{
A. Morvannou, N. Forquet, M. Vanclooster, Pascal Molle
}

\section{To cite this version:}

A. Morvannou, N. Forquet, M. Vanclooster, Pascal Molle. Characterizing hydraulic properties of filter material of a vertical flow constructed wetland. Ecological Engineering, 2013, 60, p. 325 - p. 335. 10.1016/j.ecoleng.2013.06.042 . hal-00926091

\section{HAL Id: hal-00926091 https://hal.science/hal-00926091}

Submitted on 9 Jan 2014

HAL is a multi-disciplinary open access archive for the deposit and dissemination of scientific research documents, whether they are published or not. The documents may come from teaching and research institutions in France or abroad, or from public or private research centers.
L'archive ouverte pluridisciplinaire HAL, est destinée au dépôt et à la diffusion de documents scientifiques de niveau recherche, publiés ou non, émanant des établissements d'enseignement et de recherche français ou étrangers, des laboratoires publics ou privés. 


\section{Characterizing hydraulic properties of filter material of a Vertical Flow}

\section{Constructed Wetland}

3 A. Morvannou ${ }^{\mathrm{a}}$, N. Forquet ${ }^{\mathrm{a}}, \mathrm{M}$. Vanclooster ${ }^{\mathrm{b}}$ and P. Molle ${ }^{\mathrm{a}}$

$4{ }^{a}$ IRSTEA, Freshwater systems, ecology and pollution research unit, 5 rue de la Doua-

$5 \quad$ CS70077 - 69626 Villeurbanne cedex, France

$6{ }^{b}$ Earth and Life Institute, Environmental Sciences, Université catholique de Louvain,

7 Croix du Sud 2 Box 2, B-1348 Louvain-la-Neuve, Belgium

8 Corresponding author: Ania Morvannou; +33472208618; ania.morvannou@irstea.fr

10 Abstract

11 Characterizing the hydraulic properties of filter material used in a vertical flow constructed wetland (VFCW) is a prerequisite to model wastewater treatment using

13 process-based models. The filter material is a matrix of porous mineral material and

14 organic matter that makes hydraulic characterization a difficult task. Here, we present a 15 combined laboratory and in situ approach to assess the hydraulic properties of a VFCW 16 installed at Evieu in Ain, France. The laboratory approach produces prior estimates of 17 the local properties of the different VFCW system layers. These prior estimates are 18 subsequently refined with inversely estimated parameters using the HYDRUS-1D code 19 in combination with in situ hydrodynamic measurements. Laboratory experiments 20 consisted of both direct (sand box, pressure chamber, and permeameter experiments) 21 and inverse estimates (evaporation method) of hydraulic parameters. In situ

\footnotetext{
Abbreviations

CW, Constructed Wetland; p.e., people-equivalents; RETC, RETention Curve (software); TDR, Time Domain Reflectometry; VFCW, Vertical Flow Constructed Wetland
} 
measurements were based on 5.5-day monitoring of the full-scale filter using 24 time domain reflectometry (TDR) probes installed at different depths. Applying the methodology with successive optimizations led to a reliable assessment of the hydraulic parameters of the VFCW. We conclude that the consistent representation of the hydraulic behavior of the VFCW requires in situ hydrodynamic observations combined with inverse modeling. However, to avoid the ill-posedness of the inverse problem, the number of fitted parameters should be kept to a minimum and parameter initialization need to be based on local-scale laboratory measurements.

Keywords: hydraulic properties; vertical flow constructed wetlands; laboratory measurements; in situ measurements; inverse modeling

\section{INTRODUCTION}

Constructed wetlands (CWs) are an attractive wastewater treatment technology for small communities (<2000 people-equivalents; p.e.), as their simplicity of operation, low cost and reliable treatment efficiency often fit with the limited resources small communities can allocate to wastewater treatment (Kadlec, 2000). Irstea (National

39 Research Institute of Science and Technology for Environment and Agriculture)

40 developed an innovative type of first-stage for VFCW, made of gravel instead of sand.

41 This first-stage type directly accepts raw wastewater, without the need for a preliminary settling tank. In a long-term operation, Molle et al. (2005) recorded on this first stage mean removal efficiencies of up to $80 \%$ for chemical oxygen demand (COD), $85 \%$ for

44 total suspended solids (TSS), and 60\% for total Kjeldahl nitrogen (TKN). However, 
despite recent optimization trials in terms of media depth and aeration, the first stage of this VFCW still lacks treatment efficiency, making it necessary to upgrade with a second vertical stage that increases the total surface area needed $\left(1.2 \mathrm{~m}^{2}\right.$ p. $\mathrm{e}^{-1}$ for the first stage and $0.8 \mathrm{~m}^{2} \mathrm{p} \cdot \mathrm{e}^{-1}$ for the second stage). Molle et al. (2008) further highlighted that treatment efficiency could be improved if the hydraulic behavior of the VFCW would be better understood.

The hydrodynamic of a VFCW can be analyzed by numerical models such as those included in the HYDRUS software package (Šimůnek et al., 2006). HYDRUS solves

54 the governing flow and transport equations for partially-saturated porous media and contains an extension module called CW2D dedicated specifically to the modeling of bio-geochemical processes in $\mathrm{CW}$ for wastewater treatment (Langergraber and Šimůnek, 2005). The bio-geochemical CW2D module incorporates all chemical species and degradation kinetics occurring in the wastewater treatment process. It uses an approach similar to the Activated Sludge Model (ASM) (Henze et al., 2000).

60

The numerical solution of the flow equation in HYDRUS requires detailed knowledge of the partially-saturated hydraulic properties of the VFCW porous medium. These properties are difficult to estimate because hydraulic functions are both highly non-

64 linear and variable in space. The hydraulic properties of partially-saturated porous media can be assessed by direct and indirect methods applied at laboratory scale, field scale, or both. For example, the constant or falling head method for determining

67 hydraulic conductivity can be applied on soil cores in-lab or in-field using cylinder infiltrometers (Dane and Topp, 2002). However, direct hydraulic characterization 
requires restrictive initial and boundary conditions that have limited practicability in the field. Although direct laboratory methods are more accurate, the parameters obtained often fail to reflect real field conditions, and no common procedure exists for transposing laboratory hydraulic properties into field scale hydraulic properties (Russo et al., 1991; Ritter et al., 2003). The differences between laboratory and field assessments are due to several factors, including differences in support volume, measurement scale and structural status (e.g. different macropore compositions), and hysteretic effects (Schuh et al., 1988; Basile et al., 2003). Consequently, in situ measurements are considered more appropriate for assessing the hydraulic properties of partially-saturated porous media (Zou et al., 2001; Ramos et al. 2006), especially in constructed wetlands where the impact of the reeds on the hydraulic characteristics of the filter cannot be easily measured at the laboratory scale.

The indirect methods often rely on inverse modeling and are particularly suited to in

83 situ assessments of hydraulic properties (Beven and Freer 2001; Hopmans et al., 2002;

84 Vrugt et al., 2003; Minasny and Field, 2005; Lambot et al., 2005; Šimůnek et al., 2006;

85 Durner et al., 2008). Inverse methods offer adaptable experimental procedures and impose less restrictive boundary conditions than direct methods. They can therefore be applied on transient flow experiments (e.g. Kool et al., 1987) and include different measurement variables in the objective function. Moreover, with inverse modeling, both

89 hydraulic conductivity and water retention characteristics can be assessed

90 simultaneously from a single flow experiment. In contrast to direct methods, inverse

91 methods can rigorously assess parameter uncertainty (Kool et al., 1987). Furthermore,

92 hydraulic parameters inferred from inverse methods are often more effective at 
93 describing transient flow in real flow systems. The down side is that inverse problems

94 are often ill-posed and can suffer from convergence problems (Russo et al., 1991).

95 Nevertheless, as stated by Durner et al. (2008), inverse-based approaches remain widely

96 recommended, and there are numerous examples of successful estimation of soil

97 hydraulic properties using inverse methods (see Kool et al., 1987; Romano, 1993;

98 Lambot et al., 2002; Hopmans et al., 2002; Ritter et al., 2004; Mertens et al., 2005;

99 Verbist et al., 2009, among many others).

101 Many studies have addressed the partially saturated hydraulic properties assessment

102 issue in the soil hydrological community, but few studies have attempted to address this

103 issue for particular porous media such as gravels and sands mixed with sludge as

104 retrieved in the VFCW systems. Giraldi and Iannelli (2009) carried out a laboratory-

105 scale experiment to assess the saturated hydraulic conductivity of the material in a

106 VFCW. They combined these measurements with generic estimates of the shape

107 parameters of the hydraulic functions, and subsequently modeled water content

108 distributions measured with capacitance probes in laboratory columns and in a VFCW

109 pilot plant. Using these methods, they were able to simply and rapidly identify the real

110 layout of vertical systems, and consequently highlight operational failures. Moreover,

111 they managed to assess unsaturated hydraulic parameters for the main layers (gravel

112 layers) of a vertical-flow bed using only water content measurements and saturated

113 hydraulic conductivity. Langergraber (2003) carried out an inverse modeling with the

114 HYDRUS-2D software to assess the hydraulic parameters of sand used as filter

115 material. He measured pressure potentials and water contents at different depths (each

$11610 \mathrm{~cm}$ in the main layer) as well as the effluent flow rate. The simulations using the 
117 fitted parameter set showed a good match with the measured data. Toscano et al. (2009)

118 assessed hydraulic parameters using the inverse simulation proposed in HYDRUS-2D

119 software (Šimůnek et al., 1999), with outflow measurements from a pilot-scale VFCW

120 (secondary treatment) used as input data. Although they did not compare their results

121 against laboratory assessments, the flow simulation study resulted in good correlations

122 between measured and simulated effluent flow rates for two successive loadings.

123 Similarly, Maier et al. (2009) used an inverse method considering a global optimization

124 based on a stochastic search strategy for parameters. Hydraulic calibration was also

125 carried out on the outflow rate measurement of two VFCWs filled mainly with a

126 mixture of expanded clay and sand. They maximized the fit between observed and

127 simulated filter discharges and revealed potential parameter correlations between certain

128 hydraulic parameters. Another experiment performed on a laboratory sand column used

129 both water content and suction head measurements to constrain the inversion (Forquet 130 et al., 2009).

132 Although several studies have reported assessments of the hydraulic properties of

133 VFCWs, none has compared the performance of different hydraulic assessment methods

134 specifically in the VFCW setting. Furthermore, there are no published reports allowing

135 the evaluation of different assessment procedures for the specific case of the French-

136 type VFCW, where a sludge layer develops at the filter surface. In this paper, we

137 compare the hydraulic properties of the first stage of a French-type VFCW estimated by

138 direct and inverse laboratory methods as well as by inverse modeling using water

139 content and outflow data collected on a VFCW. The objective is to determine the most

140 appropriate method to estimate the hydraulic parameters in this type of VFCW. 


\section{MATERIALS AND METHODS}

145 The Evieu wastewater treatment plant (Ain, France) comprises a sequence of vertical

146 and horizontal sub-surface flow constructed wetlands. The plant has been in operation

147 since 2004. It was originally designed for 200 p.e., but as only 100 p.e. are currently

148 connected, the filter surface has been divided into two stages to work at full capacity.

149 The first stage is made up of three VFCWs receiving raw wastewater. The pump sump

150 at the plant inlet only performs mechanical screening using a $5 \mathrm{~cm}$ mesh screen. Each

151 filter is fed according to a feeding/rest regime of 3.5/7 days. Effluent from this first stage is then connected to a second pump sump and separated between the second stage's vertical and horizontal flow constructed wetlands according to the experimental objectives (Molle et al., 2008). All beds are planted with reeds (Phragmites australis).

156 This study focuses on one of the filters of the first stage. The selected vertical filter (28

$157 \mathrm{~m}^{2}, 2.9 \mathrm{~m}$ wide $\mathrm{x} 9.7 \mathrm{~m}$ long) is designed according to French recommendations. From

158 the bottom to the top, it contains a $15 \mathrm{~cm}$ thick drainage layer (grain size of 30-60 mm),

159 a $10 \mathrm{~cm}$ transition layer (grain size $15-25 \mathrm{~mm})$ and a $60 \mathrm{~cm}$ gravel layer $\left(\mathrm{d}_{10}=2.46 \mathrm{~mm}\right.$;

$160 \mathrm{UC}=\mathrm{d}_{60} / \mathrm{d}_{10}=1.39$; average porosity of $40.4 \%$ ). As the filter has been working at

161 nominal load for 7 years, a sludge layer of about $20 \mathrm{~cm}$ has developed at the top of the

162 filter. The VFCW is fed by raw wastewater in batches of $5 \mathrm{~cm}$ at a rate of $1.23 \mathrm{~m} \mathrm{~h}^{-1}$ on 163 average. During spells of dry weather, 8 separate batches of $3.4 \mathrm{~min}$ on average are 
164 processed per day. Water is drained by a $160 \mathrm{~mm}$ diameter drainage pipe $(0.42 \mathrm{~m}$ of 165 pipe per $\mathrm{m}^{2}$ ), allowing passive aeration from the bottom as well.

168 We monitored the VFCW hydrodynamic behavior to estimate its hydraulic parameters 169 using inverse modeling. To monitor water contents in the VFCW, a set of 24 TDR 170 probes was installed one year before the experiment to minimize measurement 171 disturbances. Six installation pits were dug in the VFCW, 4 probes were installed at 172 different depths in each pit (Fig. 1), and the pits were then refilled. As found in 173 preliminary observations, sludge and gravel proportion varies according to filter depth, 174 with the result that biomass growth and solid entrapment in the porous gravel become 175 increasingly limited with depth. Several layers, each presenting different hydraulic 176 behaviors, can be differentiated. To perform inverse modeling, we hypothesized that the 177 VFCW is composed of 4 horizontal layers (from top to bottom): sludge deposit (Layer $1781, \mathrm{~h}_{1}=20 \mathrm{~cm}$ thick), biomass-colonized gravel (Layer 2, $\mathrm{h}_{2}=20 \mathrm{~cm}$ thick), less 179 biomass-colonized gravel (Layer $3, \mathrm{~h}_{3}=20 \mathrm{~cm}$ thick), and almost-clean gravel (Layer 4, $180 \mathrm{~h}_{4}=20 \mathrm{~cm}$ thick). Probes were inserted at four different depths corresponding to this 181 layering system, and connected through multiplexers to a signal generator/analyzer 182 (model TDR100, Campbell Scientific ${ }^{\mathrm{TM}}$, Logan, UT). Results were recorded using a 183 datalogger (model CR1000, Campbell Scientific ${ }^{\mathrm{TM}}$ Logan, UT). Measurements were 184 made at 1 minute time intervals, end-to-end throughout the monitoring campaign, 185 including the 3.5 batch feeding days and the first two days of the rest period. Three 186 tensiometers were installed at different depths of the VFCW. Unfortunately, pressure 
187 head variations were too small to be recorded by the monitoring device. Therefore, we

188 only used water contents for assessing the hydraulic parameters.

INSERT FIG 1

190

192 In this study, we modeled the hydraulic properties of the VFCW sludge and gravel

193 layers using van Genuchten-Mualem closed-form expressions (van Genuchten, 1980;

194 Mualem, 1976):

$195 \quad \theta(\mathrm{h})=\theta_{\mathrm{r}}+\frac{\theta_{\mathrm{s}}-\theta_{\mathrm{r}}}{\left[1+|\alpha \mathrm{h}|^{\mathrm{n}}\right]^{\mathrm{m}}} \quad \mathrm{h}<0$

196 where $h>0$ and $\mathrm{m}=1-1 / \mathrm{n} ; h(\mathrm{~L})$ is the actual pressure head; $\theta(h)\left(\mathrm{L}^{3} \mathrm{~L}^{-3}\right)$ is the actual

197 water content dependent on $h ; \theta_{\mathrm{r}}$ and $\theta_{\mathrm{s}}\left(\mathrm{L}^{3} \mathrm{~L}^{-3}\right)$ are the residual and saturated

198 volumetric water contents respectively; $\alpha\left(\mathrm{L}^{-1}\right)$ and $n(-)$ are shape parameters; and

$\mathrm{K}(\theta)=\mathrm{K}_{\mathrm{s}} \mathrm{S}_{\mathrm{e}}^{\lambda}\left[1-\left(1-\mathrm{S}_{\mathrm{e}}^{1 / \mathrm{m}}\right)^{\mathrm{m}}\right]^{2}$

200 where $\mathrm{S}_{\mathrm{e}}=\left(\theta-\theta_{\mathrm{r}}\right) /\left(\theta_{\mathrm{s}}-\theta_{\mathrm{r}}\right)$ (dimensionless) is the effective fluid saturation; $K(\theta)\left(\mathrm{L} \mathrm{T}^{-}\right.$

$201^{1}$ ) is the actual hydraulic conductivity dependent on the actual water content $\theta ; K_{S}\left(\mathrm{~L} \mathrm{~T}^{-}\right.$

$\left.202^{1}\right)$ is the saturated hydraulic conductivity; and $\lambda(-)$ is the Mualem pore connectivity 203 parameter.

205 Eq. (1) contains four independent parameters $\left(\theta_{\mathrm{r}}, \theta_{\mathrm{s}}, \alpha\right.$, and $\left.n\right)$, while the hydraulic conductivity equation (Eq. (2)) integrates the saturated hydraulic conductivity $\left(K_{s}\right)$ and

207 the Mualem pore connectivity parameter $(\lambda)$. This parameter was fixed at 0.5 . To limit 208 the total number of parameters to be assessed during the inversion, and following 209 Ramos et al. (2006), we set $\theta_{\text {s }}$ for gravel equal to the total porosity. Total porosity is 
210 easy to calculate from the dry bulk and particle densities (Flint and Flint, 2002). Setting

$211 \theta_{\mathrm{s}}$ equal to total porosity is challenged by several authors, who suggest that $\theta_{\mathrm{s}}$ might be

212 smaller than total porosity due to entrapped air or the presence of flow irregularities

213 (Wessolek et al., 1994; Richard et al., 2001). We hypothesized that this is particularly

214 true for finer-textured porous media or natural soil, but less applicable for gravel.

215 Consequently, we fixed $\theta_{\mathrm{s}, \text { gravel }}$ to total porosity and only optimized $\theta_{\mathrm{s}, \text { sludge }}$.

217 Recalling that (i) in situ measurements provide more representative parameter values

218 than laboratory measurements despite being more difficult to set up, and that (ii) inverse

219 methods take better into account the transient nature of unsaturated flow than the direct

220 methods carried out on permanent flow condition, different parameter assessments were

221 developed using both laboratory and in situ measurements and both direct and inverse

222 methods for the remaining parameters in Eq. (1) and (2).

2.3.1 Laboratory scale experiments

\subsubsection{Samples}

227 Samples were collected at different depths of the VFCW to assess the local-scale 228 hydraulic properties of the different layers. We used a sampling technique that minimizes sample compaction to keep original sample structure and porosity. A total of

230 six samples were extracted using PVC cylinders $($ diameter $=15 \mathrm{~cm}$, height $=11 \mathrm{~cm})$ :

231 one sample from Layer 1, two samples from Layer 2, three samples from Layer 4.

232 Samples from Layer 3 were not studied because of the damage that occurred during the transport of the sample. The drainage layer was not studied, based on the assumption 
234 that its role in the hydraulic behavior of the filter can be neglected when compared to 235 the hydraulic role of the upper layers.

\subsubsection{Determination of saturated hydraulic conductivity}

238 The $K_{s}$ of the VFCW samples was determined directly by applying the constant-head

239 soil core method (Klute and Dirksen; 1986; Reynolds and Elrick, 2002). This technique

240 is suitable for measuring the hydraulic conductivity of highly permeable materials like

241 sand and gravel $\left(10^{0}\right.$ to $10^{-5} \mathrm{~cm} \mathrm{~s}^{-1}$, Reynolds and Elrick, 2002). The sample cores were

242 first mounted on coarse mesh covered by nylon and then they were saturated by placing

243 them in a tank filled with water for a $24 \mathrm{~h}$ period before measuring $K_{s}$. Measurements

244 were repeated three times for each sample (except for Layer 1 that was only measured 245 once due to the slow water flow rates). Each sample was then subjected to an 246 evaporation method and subsamples of them were used in a sand box and pressure 247 chamber methods. We also measured the volatile matter content for each sample by

248 loss-on-ignition to compare $K_{s}$ values with organic matter content: subsamples extracted 249 from the core samples using $100 \mathrm{~cm}^{3}$ stainless steel rings were dried at $105^{\circ} \mathrm{C}$ and then $250550^{\circ} \mathrm{C}$ to assess the dry matter and the volatile matter contents, respectively.

\subsubsection{Water retention curves}

253 After determining $K_{s}$, one undisturbed subsample of each previous sample was extracted

254 from the core samples using $100 \mathrm{~cm}^{3}$ stainless steel rings. A sand box (Stackman et al., 255 1969) was used to determine water retention at low suctions up to $10 \mathrm{kPa}(0.1,1,3.2$

256 and $6 \mathrm{kPa}$ ). The samples were subsequently moved to a pressure chamber to determine

257 water retention at high suctions up to $1.5 \mathrm{MPa}(0.025,0.1$ and $1 \mathrm{MPa})$. The van 
258 Genuchten-Mualem model (Eq. (1)) was fitted to the experimental water retention data 259 using the RETC program (van Genuchten et al., 1991). Because $\theta_{\mathrm{s}}$ was fixed using the 260 porosity value, only the residual water content $\theta_{\mathrm{r}}$ and the shape parameters $\alpha$ and $n$ were

261 fitted for Layers 2 and 4. To make the comparison and interpretation of water retention 262 curves between layers easier, we used a cluster approach. This approach enables to 263 overcome the difficulties related to the number of parameters $\left(3: \theta_{\mathrm{r}}, \alpha\right.$ and $\left.n\right)$ and the 264 non-linear relationship between them. The aim of this approach is to regroup layers in a 265 limited number of functional layers based on the similarity of the water retention 266 curves, as expressed by the Euclidean distance between them.

\subsubsection{Evaporation method}

The evaporation method is a transient inverse technique for determining unsaturated hydraulic conductivity and water retention curves at the laboratory scale (Wind, 1968;

271 Ciollaro and Romano, 1995; Santini et al., 1995; Hopmans et al., 2002). The method 272 inverts the governing flow equation using measured transient evaporation rates from a 273 saturated soil sample.

275 The evaporation method was applied on the samples directly after the saturated 276 hydraulic conductivity measurements when samples were still saturated. The samples 277 were sealed at the bottom and placed under a free-evaporation boundary condition at the 278 top (i.e. air humidity and temperature were not controlled). Usually, this method is 279 carried out with some tensiometers to measure matric potentials and TDR probes for 280 monitoring water content evolutions. In this study no tensiometers were used, but only 281 TDR probes. TDR probes were inserted at two different depths $(0.03 \mathrm{~m}$ from the top, 
282 TDR A, and at $0.03 \mathrm{~m}$ from the bottom, TDR B) as illustrated in Fig. 2. Each TDR

283 probe comprises three rods (100 $\mathrm{mm}$ length, $3 \mathrm{~mm}$ internal diameter, $15 \mathrm{~mm}$ spacing

284 between rods). TDR measurements were taken on a Tektronix ${ }^{\mathrm{TM}}$ 1503B oscilloscope.

285 The relationship between dielectric constant and water content was obtained by a

286 material-specific calibration (Topp et al., 1980). Samples were weighed two to three

287 times per day at the beginning of the experiment and only once a day after evaporation

288 rate decreased. Once daily losses became negligible (less than $10 \mathrm{mg}$ of water

289 evaporated in $24 \mathrm{~h}$ ), the experiment was stopped. The weight loss due to the loss of

290 organic carbon during the evaporation experiment was neglected compared to the

291 evaporation process.

\section{INSERT FIG 2}

293

294 The hydraulic parameters $\left(\theta_{\mathrm{r}}, \theta_{\mathrm{s}_{-} \text {sludge }}, \alpha, n\right.$ and $\left.K_{S}\right)$ of the six samples were determined 295 using the inverse modeling tool in HYDRUS 1-D using measured soil water content and 296 evaporation rates. Hydraulic parameter values derived from the earlier constant-head,

297 sand box and pressure chamber experiments were used as starting values for inverse 298 modeling. Samples were considered as initially saturated. Boundary conditions were 299 expressed in terms of water fluxes: no flux at sample bottom and variable flux at top.

300 The measured cumulative evaporation was interpolated, and the instantaneous fluxes 301 were implemented as top boundary conditions. From the water content data we 302 minimized the objective function in HYDRUS-1D model using the Levenberg303 Marquardt nonlinear minimization algorithm (Marquardt, 1963). An equal weight was 304 assigned in the model for all water content data during optimization (weight $=1$ ). The 305 mean and the variance of each optimized hydraulic parameter value obtained by this 
306 method are only representative of the quality of the optimization process and are not

307 constrained by physical limits (unphysical values). This may result in parameter

308 intervals which violates the physics of the system. In order to constrain the parameter

309 estimates to physical limits, we updated a-priori physical parameter ranges with

310 information from the evaporation experiment using a Bayesian updating approach.

311 Within the Bayesian framework a prior distribution is specified to reflect an a priori

312 knowledge of the physical range of variation (Feyen et al., 2002) of a parameter p: $f(p)$.

313 For example, the prior distribution for the $\theta_{\mathrm{r}}$ parameter can range from 0 to the $\theta_{\mathrm{s}}$ value.

314 The distribution obtained from the inversion considering the evaporation data set, $\mathrm{y}$,

315 will be called the likelihood function $\mathrm{Ly}(\mathrm{p})$, and will be multiplied to the prior

316 distribution to produce a posterior distribution $\mathrm{f}(\mathrm{p} \mid \mathrm{y})$ according to Eq. (3).

$317 \quad \mathrm{f}(\mathrm{p} \mid \mathrm{y})=\mathrm{c} \cdot \mathrm{f}(\mathrm{p}) \cdot \operatorname{Ly}(\mathrm{p})$

318 where $\mathrm{c}(-)$ is a constant adjusted to ensure that the integral of $\mathrm{f}(\mathrm{p} \mid \mathrm{y})$ on $p$ is equal to 1.

319 The choice of the prior distribution is "subjective" but we expect that the likelihood

320 function will "dominate the resulting posterior distribution" (Feyen et al., 2002).

\subsubsection{Inverse modeling using in situ measurements}

323 Not all data were used from the in situ monitoring; instead we selected water contents

324 from one particular batch with a long drainage period that was recorded at night (Fig.

325 5). This reduced the size of the dataset to enable faster optimization, while providing a

326 sufficiently large variation in water content to enable better hydraulic parameter

327 estimates. The mean values of the hydraulic parameters optimized from the evaporation

328 experiment were used as starting values to invert the in situ water content data using

HYDRUS-1D. The transition and drainage layers (bottom two layers) were assumed not 
330 to constrain the flow. Furthermore, the design of the drainage system includes a sump

331 that temporarily stocks water between the drainage pipe and the outflow measurement

332 device. Consequently, the measured outflows are not representative of those leaving the

333 drainage pipe and cannot be used for the model inversion. So we restrain the domain to

334 the sludge and filter layers. The one-dimensional mesh used for simulations consisted of

335101 nodes. The top boundary condition is a time-dependent atmospheric boundary 336 condition with a threshold value for surface runoff set to $100 \mathrm{~cm}$. Wastewater load

337 duration and flow rate are specified (mean: $1.94 \mathrm{~m}^{3}, 0.05 \mathrm{~m} \mathrm{~s}^{-1}$ ), while evaporation is

338 neglected. If the incoming flow rate exceeds infiltration capacity, the ponding of water

339 above the surface is then taken into account until it reaches $100 \mathrm{~cm}$, a value that never

340 observed in our case. The bottom boundary condition is a seepage face. An equal weight

341 was assigned in the model for all water content data during optimization (weight $=1$ ).

342 The setup of initial conditions necessitated a prior initialization step. We could not use

343 observed water contents since they do not provide a continuous pressure head profile at

344 the initial time and cause the model not to converge (Radcliffe and Šimůnek, 2010). The

345 prior initialization step consists in a simulation where loads $\left(1.87 \mathrm{~m}^{3}, 0.04 \mathrm{~m} \mathrm{~s}^{-1}\right.$, each)

346 are applied at a constant time-lapse until pressure heads reach a pseudo-permanent state

347 starting from hydrostatic distribution. We then selected the time for which water content

348 profile matches the experimentally-observed initial water content. The corresponding

349 water pressure profile was then considered as initial condition. The five van Genuchten-

350 Mualem parameters $\left(\theta_{\mathrm{r}}, \theta_{\mathrm{s}_{-} \text {sludge }}, \alpha, n\right.$ and $\left.K_{s}\right)$ were estimated simultaneously, for each

351 vertical profile. However, to avoid ill-posedness problems, the parameters were

352 estimated layer-by-layer, from top to bottom. 
354 Next, parameter distributions obtained from the inverted in situ observations were combined with the same prior distribution (physical limits) as presented in section 2.3.1.4 using the Bayesian data fusion approach. In summary, this procedure yields the hydraulic parameter distribution at the scale of the vertical profile in the filter.

359 Furthermore, to evaluate the robustness of the inverse approach, we tested different

360 initial parameter values: those obtained from direct laboratory experiments and generic 361 parameter values available in HYDRUS. filter.

365 After optimizing hydraulic parameters for each vertical profile, we combined them layer-by-layer to obtain the parameter set probability density distribution (pdf) at the scale of the filter. This final parameter set pdf accounts both for spatial variability of the

368 local properties within the filter and uncertainties associated with the local estimates.

369 However, the pdf of some local scale parameters exhibit large confidence intervals due to a poor optimization or significantly differ from similar parameters obtained for the

371 same layer. These values were considered as outliers and consequently removed before 372 upscaling. In this procedure, we simply considered that the effective filter scale 373 parameter equals the mean of the profile scale parameters. Such upscaling is acceptable 374 if lateral flow between the profiles in the filter can be ignored as compared to the 375 vertical flow. Then, layer-by-layer and parameter-by-parameter, the final value was computed. Since parameter pdfs were not all normally distributed, we used the convolution theory for combining random variables: 
379 were $f$ and $g$ are the two pdfs for which the convolution product $(f * g)$ is calculated.

380 We initially combined pdfs of the two first profiles. Then, we successively combined

381 the result with the pdf of the next profile. This is possible because the convolution

382 product is associative.

383

\subsection{Model validation}

385 Following the inverse-modeled parameter identification, hydrodynamic modeling was

386 done using HYDRUS 1D software, including the remaining fraction of the monitoring

387 dataset. Flow domain and boundary conditions were identical to those used for in situ

388 data inversion. The setup of initial conditions was obtained using a prior initialization

389 step as described in section 2.3.2. We calculated the mean square relative error (MSRE,

390 Eq. (5)) to evaluate the agreement between simulation results and measured water

391 contents (precision of the model simulation). The lower value of this MSRE is, the

392 better agreement between observation and simulation is.

$393 \quad M S R E=\frac{1}{N} \sum_{i=1}^{N}\left[\left(O_{i}-P_{i}\right) / O_{i}\right]^{2}$

394 where $i=1: N$ is the time interval ( 1 minute) end-to-end throughout the monitoring 395 campaign, with $N$ being the number of data (water contents) collected during the monitoring period (i.e. $N=7780$ ); $O_{i}$ is the water content observed for the time $i ; P_{i}$ is

397 the water content predicted for the time $i$.

\section{RESULTS AND DISCUSSION}


402 Based on porosity estimates, the $\theta_{\mathrm{s}}$ values were fixed to $40.6 \%$ for Layers 2 and 3 , and $44.0 \%$ for Layer 4.

404

405

\subsubsection{Saturated hydraulic conductivity determination}

406 Table 1 gives the $K_{s}$ values and the volatile matter contents for all 4 VFCW layers

407 considered.

408 INSERT TABLE 1

409

410 As expected, $K_{s}$ values were proportional to pore size. However, for Layer 1, we

411 identified issues over the reliability of the $K_{s}$ value and the method used. First, the

412 sludge layer is characterized by significant shrinking-swelling behavior. The constant

413 head soil core method is inappropriate for determining the $K_{s}$ of porous media of

414 variable geometry (Reynolds and Elrick, 2002). Second, the $K_{s}$ value for Layer 1 is

415 close to the lower boundary of the method's range of validity $\left(10^{-5} \mathrm{~cm} \mathrm{~s}^{-1}\right)$. We also

416 noted that the $K_{s}$ values for Layers 2 and 4 were very close: $K_{s-L 2}$ is 1.06 times higher

417 than $K_{s-L 4}$. This is somewhat surprising given that Layer 2 contains more organic matter 418 than Layer 4.

\subsubsection{Water retention curves}

421 The water retention curves as determined both on the sand box and in the pressure 422 chamber apparatus are given in Fig. 3. At equal applied pressure, sample water content 423 increases with increasing proportion of organic matter. The shape of the water retention 424 curve is consistent with Aubertin et al. (2003). For all gravel samples, water content 
rapidly reaches residual water retention after only few pressure steps. Furthermore, the reliability of measurements close to saturation is debatable, particularly for the coarse gravel material, as there may be significant water loss when handling the samples in the sand box and pressure chamber experiments. For the sludge layer higher residual water content could probably be measured at higher pressure steps.

\section{$430 \quad$ INSERT FIG 3}

432 Based on these data, and with saturated water content fixed to porosity (except for 433 Layer 1), hydraulic parameters were fitted for every sample. Results are presented in 434 Table 2 and the cluster approach result is presented in Fig. 4. The cluster approach 435 indicates that the curve corresponding to Layer 1 is the most dissimilar from the other 436 curves. The sludge layer has a significantly higher capability to retain water than the 437 other layers. The second node from the top in the tree representation of the cluster 438 approach separates samples from layers 2 and 4 that is consistent with their different 439 organic matter contents. Euclidean distance between samples of Layer 2 is greater than 440 those between samples of Layer 4. Cross-comparison of hydraulic parameters between 441 each sample of Layer 2 revealed significant differences for $\theta_{\mathrm{r}}$ and $\alpha$ values $\left(\mathrm{t}-\theta_{\mathrm{r}}=8.3\right.$, $\mathrm{t}-$ $\left.442 \alpha=-4.3, \mathrm{p}<1.10^{-6}\right)$. On the contrary, the Student's $t$-test applied to parameters of Layer 4434 showed that $\theta_{\mathrm{r}}$ and $\alpha$ values are close $\left(\mathrm{t}-\theta_{\mathrm{r}}=-0.2, \mathrm{t}-\alpha=-1.4, \mathrm{p}>0.005\right)$, except for the 444 sample 4-3.

445 INSERT TABLE 2

446 INSERT FIG 4 
448 Table 2 highlights that the parameter values obtained are consistent with a simple 449 physically-based porous flow modeling concept. Indeed, $\alpha$ will be smaller and $\theta_{\mathrm{r}}$ will be

450 higher as organic matter content increases, reflecting the impact of organic matter on the

451 structure of the porous medium. The $n$ parameter values were similar for all gravel452 containing samples. Relatively high sludge proportions had no significant impact on this 453 parameter.

\subsubsection{Evaporation method}

456 Table 3 presents the hydraulic parameter values obtained from the evaporation

457 experiments. For Layer 2, using the t-test as in section 3.1.2, most of optimized 458 parameter values are dissimilar, except for the $\theta_{\mathrm{r}}$. However, as for the results from the water retention curves, parameters values were similar for two out of three (4-1 and 4-2) of the layer-4 samples. In addition, no clear trend emerged when comparing $\theta_{\mathrm{r}}, \alpha$ and $n$

461 between layers.

463 The parameter values from the evaporation experiment (Table 3) significantly differed 464 and tended to be lower than those estimated by the direct method (Table 2), with an 465 important exception for the $\theta_{\mathrm{s}}$ value of Layer 1 which increased. However, the degree of 466 reliability of parameters assessed by the evaporation method should be considered low, 467 as illustrated by the wide confidence intervals obtained from the inverse optimization 468 method. In addition, the strong correlation between hydraulic parameters (between $\theta_{\mathrm{r}}$ 469 and $\alpha$ particularly, the correlation coefficient ranges from 0.53 to 0.99 ) from inverse 470 optimization (correlation matrix not shown) indicates also that hydraulic parameter 471 values showed a high level of uncertainty (Šimůnek et al., 1998). Indeed, water content 
472 did not decrease very low during evaporation experiments: $\theta_{\mathrm{r}}$ and $\alpha$ values are 473 consequently highly uncertain. Several problems may explain this low reliability. First, 474 the evaporation method does not provide reliable estimation of hydraulic properties at 475 near-saturation when sample cores are initially saturated, as was the case in this study. 476 Indeed, for soils with a high structural porosity, Richard et al. (2001) found that the 477 retention properties were overestimated and hydraulic conductivity underestimated 478 when the evaporation experiment started from fully-saturated samples. Stolte et al. 479 (1994) suggested conducting the evaporation method without the preliminary saturation 480 step. Secondly, non-optimal experimental conditions likely biased the evaporation 481 measurements. The contact between TDR probes and porous material may become 482 problematic due to air entry during the measurements. This is particularly problematic 483 for the sludge sample, which strongly shrinks during drying (Vincent et al., 2011). 484 Furthermore, the low frequency of sample weighting leads to poor estimates of the real 485 evaporation rate since we operated in non-controlled climatic conditions. This could had 486 been avoid by continuous monitoring of sample weight.

\section{INSERT TABLE 3}

\subsubsection{In situ measurements}

490 Figure 5 presents water content data measured at various depths in the VFCW $(13,31$, 49147 and $62 \mathrm{~cm}$ below the VFCW top surface) for the vertical profile 2 together with the 492 experimental uncertainties estimated by media-specific calibration. The fact that the 493 sludge layer has a high electrical conductivity resulted in fairly significant signal loss in 494 this layer for some water content measurements. 
497 Water content variations monitored by TDR probes allow identifying all the batches of

498 water added to the VFCW (Fig. 5). Each batch is easily identifiable by the increase of

499 the water content. In addition, the water retention and hence the water content decreases

500 with depth, as organic matter content is lower deeper in the filter.

\section{$501 \quad$ INSERT FIG 6}

503 Results from the in situ data inversion are presented in Fig. 6. For Layer 1, parameters

504 are dispersed and the confidence intervals for $K_{s}$ and $n$ values do not overlap for the

505 different horizontal positions in the VFCW. Mean $\theta_{\mathrm{r}}$ values did not significantly differ

506 for Layers 2, 3 and 4 for all vertical profiles ( $\mathrm{p}>0.002$ ). Values for $K_{s}, \alpha$ and $n$ were

507 also similar between vertical values within a same given layer $(\mathrm{p}>0.0017)$, thus

508 demonstrating the reliability of the inversion from field data.

509

510 Inverse modeling using in situ data could be even more robust if more information

511 (such as measured VFCW outflow) were included in the objective function. However,

512 this was not possible based on the filter design issue presented in the section 2.3.2. A

513 possible solution could have been to set up a transfer function to account for the buffer

514 effect of the temporary storage between the filter and the outflow measurement device.

515 Because of the issues concerning the tensiometers their values were neither used in the 516 objective function. 
519 After removing the outliers, the set of parameters validated for each vertical profile was

520 then combined to obtain the overall global VFCW-scale parameter set. Table 4 gives the

521 means and the standard deviations of the global hydraulic parameters. Results mostly

522 differ from values obtained by lab-methods, which is consistent with Mertens et al.

523 (2005). Notice that the residual water content of Layer 1 is very high given that the

524 sludge consists of around $75 \%$ water and its desaturation takes a long time. It is a media 525 very difficult to characterize and its physical properties rapidly change (due to 526 swelling/shrinking). While for Layers 2, 3 and 4 the saturated water content was fixed 527 to the porosity, it was optimized for the sludge layer.

528 INSERT TABLE 4

530 Comparing laboratory defined (Tables 2 and 3) vs. in situ measured reference

531 parameters (Table 4) showed that laboratory methods gave good estimations of 532 reference $K_{s}$ value but underestimated the $\theta_{\text {r }}$ and $\alpha$ values, and $n$ values were too 533 dispersed to draw any firm conclusions. These patterns contrast with the conclusions of 534 Kumar et al. (2010), who showed that field-scale $\theta_{\mathrm{r}}, \theta_{\mathrm{s}}$ and $n$ parameters could be 535 estimated from laboratory experiments but that inverse modeling with in situ data was 536 needed for $\alpha$ and $K_{s}$. These differences with the conclusions of Kumar et al. (2010) can 537 mainly be explained by the fact that their study was carried out on soil samples and 538 partly explained by the inappropriate operation conditions of the evaporation method in 539 this study. 
542 Figs. 7 and 8 present observed and simulated water contents in the VFCW for vertical

543 profile 2. Simulations were performed with parameters obtained from (i) the inversion

544 of in situ water content data (Fig. 7), (ii) the direct laboratory method (Fig. 8, left), and

545 (iii) the inverse laboratory method (Fig. 8, right). Estimated parameters from method (i)

546 were considered as reference parameters. Figure 8 illustrates that parameter sets

547 obtained by the two laboratory methods are unable to properly simulate the water

548 contents observed in the VFCW. We calculated square relative differences (MSRE

549 values) of $11.8 \%$ and $5.3 \%$ for estimates with direct laboratory parameters and inverse

550 laboratory parameters, respectively.

$551 \quad$ INSERT FIG 7

552 INSERT FIG 8

553

554 One advantage of the multi-tier approach developed in this article is that we can

555 improve the identifiability of the poorly-posed inversion problem. We experienced

556 convergence difficulties with the inverse modeling of in situ data carried out directly

557 with hydraulic parameter estimates from the direct laboratory experiments. Indeed,

558 when parameter estimates only from direct laboratory experiments for initialization

559 were used, we were able to obtain a parameter set by inverse modeling over one batch,

560 but direct model failed to simulate the entire monitoring campaign. When only using

561 generic parameter databases available in HYDRUS, we failed to obtain a parameter set

562 by inverse modeling. Ritter et al. (2003) showed that laboratory methods are useful to

563 properly initialize inverse methods for estimating hydraulic parameters, and can be used

564 to reduce the number of fitting parameters. Confidence intervals generally decrease over

565 the course of successive hydraulic parameter estimation and optimization processes. 
566 Therefore, a stepwise optimization process maximizes information exploitation from the

567 various experiments while keeping the objective function as close as possible to its

568 global minimum. Furthermore, this method tends to minimize the effect of extreme

569 values stabilizing the solution at the cost of a loss of information.

570

571 We found that $K_{s}$ parameter values were similar for Layer 2 for the different approaches used (Fig. 9). As expected, $K_{s}$ scales negatively to sludge content and consequently increases with depth as sludge content decreases. This close agreement between the different determination techniques is apparent, given that $K_{s}$ can normally vary significantly at short distances. These results contrast with many soil science studies showing that $K_{s}$ at core scale in the laboratory is not effective for modeling in situ transport (e.g. Mallants et al., 1996).

INSERT FIG 9

580 Parameter $\theta_{\mathrm{r}}$ appeared to be difficult to determine with the inverse method (see max CI,

581 Table 4), particularly when organic matter content was high, as was the case for Layers

5821 and 2. For these specific layers, a non-equilibrium flow approach would probably be more appropriate, as not all the porosity would participate in water flow.

585 The $\alpha$ value was lower for Layer 1 than for Layers 2 and 3, as expected (Table 4).

586 However, the change in values for Layers 2 and 4 when switching from the direct to the inverse laboratory method is not expected. Again, experimental bias in the evaporation method may explain this pattern. For Layers 2 and 4, $\alpha$ was always underestimated by laboratory methods. This could be explained by non-equilibrium flow and hysteresis. 
590 Indeed, non-equilibrium preferential flow may have occurred in the VFCW. In such

591 cases, it is expected that $\alpha_{\text {non-equilibrium flow }}>\alpha_{\text {equilibrium flow }}$ due to a significant effect of

592 macropores on unsaturated flow (Feyen et al., 1998). However, it is still difficult to

593 obtain reliable estimates of non-equilibrium flow parameters using inverse modeling

594 data (Šimůnek et al., 2003; Laloy et al., 2010), and $\alpha_{\text {non-equilibrium flow }}$ is consequently

595 subject to a large degree of uncertainty. Hysteresis may also explain the observed

596 differences, because laboratory methods represent drying processes while field

597 measurements represent drying and wetting processes.

598

599 Both the modeling process and the model parameters were validated on the remainder

600 of the monitoring dataset. As shown in Fig. 7, the simulation of water contents was

601 good for most of the layers in the first four batches, where predicted water contents

602 were close to observed water contents $(\mathrm{MSRE}=0.6 \%)$. For later batches, the MSRE

603 increased, which can be explained by the fact that the applied model does not consider

604 water accumulation due to biomass growth, presence of organic matter, and the build-up

605 of total suspended solids in the filter.

606

607 During the rest period, model predictions were unable to accurately reproduce the

608 observed decrease in water content. The lowest absolute difference between observed

609 and simulated water contents was found for Layer 1. Nevertheless, for a mature system

610 like the Evieu VFCW plant, we consider that water content can be adequately simulated

611 over a three-days feeding period. This would probably not be the case for a longer

612 simulation or for a less mature system where biomass growth and suspended solid

613 deposits during a given feeding period is expected to have a greater impact on hydraulic 
614 parameters. Unfortunately, our experimental set-up did not enable us to validate the

615 model in these conditions.

616

\section{CONCLUSION}

618 The calibration of hydraulic properties for a VFCW was carried out using laboratory

619 and field data, and the HYDRUS software. As observed in the VFCW, vertical

620 heterogeneity of hydraulic properties is important. Four layers composing the VFCW (a

621 sludge layer, two layers for the mix between sludge and gravel and a gravel layer) were

622 used in the conceptual and numerical models to describe its hydraulic behavior.

623 However, this number of layer was arbitrary and we did not attempt to optimize it.

625 We used a multi-tier approach to obtain a hydraulic parameter set for these various

626 layers. Both direct and inverse laboratory experiments and a network of TDR probes

627 inserted within the VFCW were used to obtain specific hydraulic parameters. The 628 applied methodology with successive optimizations as well as a large range of 629 experimental data led to a reliable hydraulic parameter set that is able to predict water 630 contents at different in-VFCW depths. Contrarily, using data sets obtained either from 631 laboratory experiments only or from in situ data inversion using literature values for 632 initialization failed. The fact that the HYDRUS software only features a local search 633 algorithm makes initialization of the hydraulic function a critical issue when inverting 634 HYDRUS on observed VFCW water data. Here, the initialization step can only be done 635 by proceeding step by step with laboratory data. The estimation of hydraulic parameters 636 for the sludge layer was particularly challenging whether it was performed in laboratory 637 or in situ. Further research should be carried out to improve sludge flow modeling by 
638 including the effects of macropore flow and solid deformation. Nevertheless, to improve

639 this methodology, it might be interesting to consider confidence intervals from proposed

640 methods into the inversion algorithm (e.g. using a Bayesian approach). Another way to

641 improve parameter calibration is to account for the correlation among them. A change in

642 one parameter can generate a variation in highly correlated parameters, with the result

643 that none can be accurately determined. Therefore it might be useful to fix one

644 parameter based on prior knowledge and optimize the others. Finally, simulations

645 should be further improved by first considering the inter-dependence between layers

646 and then using non-equilibrium models that are able to reproduce preferential flows.

647 The former could be achieved by performing additional parameter optimizations to test

648 the robustness of the hydraulic parameter optimization and to estimate the influence of 649 layers to each others backward (e.g. by influencing the moisture content at the bottom of 650 the overlying layer).

651

652 Acknowledgements

653 The authors thank Clément Crétollier and Olivier Garcia for their valuable technical 654 assistance in installing the TDR probes in the VFCW. The authors also thank Guido 655 Rentmeesters for his assistance with laboratory experiments (CHSCM, evaporation 656 experiment, sand box and pressure head).

657

658

659

References 
660 Aubertin, M., M., Mbonimpa, B., Bussière, and R.P., Chapuis. 2003. A model to predict 661 the water retention curve from basic geotechnical properties. Can. Geotech. J. $662 \quad 40(6): 1104-1122$.

663 Basile, A., G. Ciollaro, and A. Coppola. 2003. Hysteresis in soil water characteristics as 664 a key to interpreting comparisons of laboratory and field measured hydraulic 665 properties. Water Resour. Res. 39(12):SBH131-SBH1312.

666 Beven, K., and J. Freer. 2001. Equifinality, data assimilation, and uncertainty estimation 667 in mechanistic modelling of complex environmental systems using the GLUE 668 methodology. J. Hydrol. 249(1-4):11-29.

669 Ciollaro, G., and N. Romano. 1995. Spatial variability of the soil hydraulic properties of 670 a volcanic soil. Geoderma 65:263-282.

671 Dane, J. H., and G. C. Topp. 2002. Methods of Soil Analysis. Part 4. Physical methods. $672 \quad$ SSSA Book Ser. 5. SSSA, Madison, WI.

673 Durner, W., U. Jansen, and S.C. Iden. 2008. Effective hydraulic properties of layered 674 soils at the lysimeter scale determined by inverse modelling. Eur. J. Soil Sci. $675 \quad 59(1): 114-124$.

676 Feyen, J., D. Jacques, A. Timmerman, and J. Vanderborght. 1998. Modelling water 677 flow and solute transport in heterogeneous soils: A review of recent approaches. J. 678 Agr. Eng. Res. 70(3):231-256.

679 Feyen, L., P.J. Ribeiro Jr., F. De Smedt, and P.J. Diggle. 2002. Bayesian methodology 680 to stochastic capture zone determination: Conditioning on transmissivity 681 measurements. Water Resour. Res. 38(9):31-311. 
682 Flint, A. L., and L.E. Flint. 2002. Porosity. p. 241-254. In J.H. Dane and G.C. Topp (ed.) Methods of Soil Analysis. Part 4. Physical methods. SSSA Book Ser. 5. SSSA, Madison, WI.

685

Forquet, N., A. Wanko, R. Mosé, and A. Sadowski. 2009. Diphasic Modelling of Vertical Flow Filter. Ecol. Eng. 35(1):47-56.

687

Giraldi, D., and R. Iannelli. 2009. Measurements of water content distribution in vertical subsurface flow constructed wetlands using a capacitance probe: benefits and limitations. Desalination 243:182-194.

Henze, M., W. Gujer, T. Mino, and M. van Loosdrecht. 2000. Activated Sludge Models ASM1, ASM2, asm2d and ASM3. IWA task group on mathematical modelling for design and operation of biological wastewater treatment. IWA Scientific and $\underline{\text { Technical Report No.9. Published by IWA Publishing in its Scientific and Technical }}$ $\underline{\text { Report series, UK. }}$

Hopmans, J.W., J. Šimůnek, N. Romano, and W. Durner. 2002. Simultaneous determination of water transmission and retention properties. Inverse methods. p. 963-1004. In J.H. Dane and G.C. Topp (ed.) Methods of Soil Analysis. Part 4. Physical methods. SSSA Book Ser. 5. SSSA, Madison, WI.

Kadlec, R. H. 2000. The inadequacy of first-order treatment wetland models. Ecol. Eng.

Klute, A., and C. Dirksen. 1986. Hydraulic conductivity and diffusivity: laboratory methods. In A. Klute (ed.) Methods of Soil Analysis. Part 1. Physical and mineralogical methods. SSSA Book Ser. 5. SSSA, Madison, WI. 
706 Kumar, S., M. Sekhar, D.V. Reddy, and M.S. Mohan Kumar. 2010. Estimation of soil

707 hydraulic properties and their uncertainty: Comparison between laboratory and field

708 experiment. Hydrol. Process. 24(23):3426-3435.

709 Laloy, E., M. Weynants, C. Bielders, M. Vanclooster, and M. Javaux. 2010. How 710 efficient are one-dimensional models to reproduce the hydrodynamic behavior of 711 structured soils subjected to multi-step outflow experiments. J. Hydrol. 393:37-52.

712 Lambot S., F. Hupet, M. Javaux , and M. Vanclooster. 2002. Inverse Estimation of Soil 713 Hydraulic Properties from Transient Flow Experiments using Global Optimization 714 by Multilevel Coordinate Search. Water Resour. Res. 38(11):6.1-6.15.

715 Lambot S., F. Hupet, M. Javaux M., and M. Vanclooster. 2005. Inverse modelling 716 techniques to characterize soil transport processes. p. 693-709. In I. Alvarez-Benedi 717 and R. Munoz-Carpena (ed.) Soil-water-solute processes in environmental systems. $718 \quad$ Monitoring, characterization and modelling. CRC press.

719 Langergraber, G. 2003. Simulation of subsurface flow constructed wetlands, results and 720 further research needs. Water Sci. Technol. 48(5):157-166.

721 Langergraber, G., and J. Šimůnek. 2005. Modeling variably saturated water flow and multicomponent reactive transport in constructed wetlands. Vadose Zone J. 4(4):924-938.

Maier, U., C. DeBiase, O. Baeder-Bederski, and P. Bayer. 2009. Calibration of hydraulic parameters for large-scale vertical flow constructed wetlands. J. Hydrol. 369(3-4):260-273.

Mallants, D., B. P. Mohanty, D. Jacques, and J. Feyen. 1996. Spatial Variability of 
729 Marquardt, D. 1963. An algorithm for least-squares estimation of nonlinear parameters.

$730 \quad$ SIAM Journal on Applied Mathematics, 11:431-441.

731 Mertens, J., H. Madsen, M. Kristensen, D. Jacques, and J. Feyen. 2005. Sensitivity of 732 soil parameters in unsaturated zone modelling and the relation between effective, 733 laboratory and in situ estimates. Hydrol. Process. 19(8):1611-1633.

734 Minasny, B., and D.J. Field. 2005. Estimating soil hydraulic properties and their uncertainty: The use of stochastic simulation in the inverse modelling of the evaporation method. Geoderma 126(3-4):277-290.

Molle, P., A. Liénard, C. Boutin, G. Merlin, and A. Iwema. 2005. How to treat raw sewage with constructed wetlands: an overview of the french systems. Water Sci.

Molle, P., S. Prost-Boucle, and A. Liénard. 2008. Potential for total nitrogen removal by combining vertical flow and horizontal flow constructed wetlands: A full-scale experiment study. Ecol. Eng. 34(1):23-29.

Mualem,Y. 1976. A new model for predicting the hydraulic conductivity of unsaturated porous media. Water Resour. Res. 12(3):513-522.

Radcliffe, D., and J. Šimůnek. 2010. Soil Physics with HYDRUS: Modelling and Applications. CRC Press, Taylor and Francis Group, 373 p.

747 Ramos, T.B., M.C. Gonçalves, J.C. Martins, M.Th. van Genuchten, and F.P. Pires. 2006. Estimation of soil hydraulic properties from numerical inversion of tension disk infiltrometer data. Vadose Zone J. 5(2):684-696.

Reynolds, W. D., and D.E. Elrick. 2002. Constant head soil core (tank) method. p. 804- 
753 Richard, G., J.F. Sillon, and O. Marloie. 2001. Comparison of inverse and direct 754 evaporation methods for estimating soil hydraulic properties under different tillage 755 practices. Soil Sci. Soc. Am. J. 65(1):215-224.

756 Ritter, A., F. Hupet, R. Muñoz-Carpena, S. Lambot, and M. Vanclooster. 2003. Using 757 inverse methods for estimating soil hydraulic properties from field data as an 758 alternative to direct methods. Agr. Water Manage. 59(2):77-96.

759 Ritter A., R. Munoz-Carpena, CM. Regalado, S. Lambot, and M. Vanclooster. 2004. 760 Analysis of alternative measurement strategies for the inverse optimization of the 761 hydraulic properties of a volcanic soil. J. Hydrol. 295:124-139.

762 Romano, N. 1993. Use of an inverse method and geostatistics to estimate soil hydraulic 763 conductivity for spatial variability analysis. Geoderma 60(1-4):169-186.

764 Russo, D., E. Bresler, U. Shani, and J.C. Parker. 1991. Analyses of infiltration events in 765 relation to determining soil hydraulic properties by inverse problem methodology. 766 Water Resour. Res. 27(6):1361-1373.

767 Santini, A., N. Romano, G. Ciollaro, and V. Comegna. 1995. Evaluation of a laboratory 768 inverse method for determining unsaturated hydraulic properties of a soil under 769 different tillage practices. Soil Sci. 160:340-351.

770 Schuh, W.M., R.L. Cline, and M.D. Sweeney. 1988. Comparison of a laboratory 771 procedure and a textural model for predicting in situ soil water retention. Soil Sci. Soc. Am. J. 52(5):1218-1227.

773 Šimůnek, J., D. Jacques, M.Th van Genuchten, and D. Mallants. 2006. Multicomponent geochemical transport modelling using the HYDRUS computer software packages. J. Am. Water Resour. As. 42(6):1537-1547. 
776 Šimůnek, J., N.J. Jarvis, M.Th. van Genuchten, and A. Gärdenäs. 2003. Review and 777 comparison of models for describing non-equilibrium and preferential flow and 778 transport in the vadose zone. J. Hydrol. 272(1-4):14-35.

779 Šimůnek, J., M. Šejna, and M.Th. van Genuchten. 1999. The HYDRUS-2D software 780 package for simulating two-dimensional movement of water, heat, and multiple 781 solutes in variably saturated media. Version 2.0, IGWMC - TPS - 53, International 782 Ground Water Modelling Center, Colorado School of Mines, Golden, Colorado, 251 p.

784 Šimůnek, J., O. Wendroth, and M.Th van Genuchten. 1998. Parameter estimation analysis of the evaporation method for determining soil hydraulic properties. Soil

Stackman, W.P., G.A. Valk, and G.G. Horst. 1969. Determination of soil moisture retention. Sand box apparatus, range $\mathrm{pF} 0$ - pF2.7. ICW, Wageningen.

Stolte, J., J.L. Freijer, W. Bouten, C. Dirksen, J.M. Halbertsma, J.C., Van Dam, J.A. Van Den Berg, G.J. Veerman, and J.H.M.Wosten. 1994. Comparison of six methods to determine unsaturated soil hydraulic conductivity. Soil Sci. Soc. Am. J. 58:15961603.

Toscano, A., G. Langergraber, S. Consoli, and G.L. Cirelli. 2009. Modelling pollutant removal in a pilot-scale two-stage subsurface flow constructed wetlands. Ecol. Eng. 35(2):281-289.

Topp, G.C., J.L., Davis, and A.P., Annan. Electromagnetic determination of soil water content: measurements in coaxial transmission lines. Water Resour. Res. 16(3):574582. 
799 van Genuchten, M.Th. 1980. A closed-form equation for predicting the hydraulic $800 \quad$ conductivity of unsaturated soils. Soil Sci. Soc. Am. J. 44:892-898.

801 van Genuchten, M.Th., F. J. Leij, and S. R. Yates. 1991 .The RETC Code for 802 Quantifying the Hydraulic Functions of Unsaturated Soils, Version 1.0. EPA Report 803 600/2-91/065, U.S. Salinity Laboratory, USDA, ARS, Riverside, California.

804 Verbist, K., W.M. Cornelis, D. Gabriels, K. Alaerts, and G. Soto. 2009. Using an 805 inverse modelling approach to evaluate the water retention in a simple water 806 harvesting technique. Hydrol. Earth Syst. Sc. 13(10):1979-1992.

807 Vincent, J., P. Molle, C. Wisniewski, and A. Liénard. 2011. Sludge drying reed beds for 808 septage treatment: Towards design and operation recommendations. Bioresource 809 Technol. 102(17):8327-8330.

810 Vrugt, J.A., H.V. Gupta, L.A. Bastidas, W. Bouten, and S. Sorooshian. 2003. Effective 811 and efficient algorithm for multiobjective optimization of hydrologic models. Water 812 Resour. Res. 39(8):SWC51-SWC519.

813 Wessolek, G., R. Plagge, F.J. Leij, and M.Th. van Genuchten. 1994. Analysing 814 problems in describing field and laboratory measured soil hydraulic properties. $815 \quad$ Geoderma 64(1-2):93-110.

816 Wind, G.P. 1968. Capillary conductivity data estimated by a simple method. In Rijtema, 817 P.E., Wassink, H. (ed.) Water in the Unsaturated Zone. Vol. 1. Proceedings of the 818 Wageningen Symposium, 19-23 June 1966. Int. Assoc. Sci. Hydrol. Publ. (IASH), 819 Gentbrugge, The Netherlands and UNESCO, Paris.

820 Zou, Z.-Y., M.H. Young, Z. Li, and P.J. Wierenga. 2001. Estimation of depth averaged 821 unsaturated soil hydraulic properties from infiltration experiments. J. Hydrol. 242(1822 2):26-42. 


\section{$825 \quad$ Figure captions}

827 Fig. 1. Set-up of the in situ experiment: (left) Top view of the VFCW with the six

828 vertical profiles for the time domain reflectometry (TDR) probes. (right) Longitudinal

829 section of the VFCW with the 24 TDR probes inserted within the four layers of the

$830 \quad$ VFCW

831 Fig. 2. Set-up of the evaporation experiment

832 Fig. 3. Water retention curves determined during the sand box and pressure chamber 833 experiments

834 Fig. 4. Cluster analysis of the water retention curves ordered by similarity using the

835 Euclidean distance between them

836 Fig. 5. Water contents and their uncertainties from time domain reflectometry (TDR)

837 probe calibration at various VFCW depths (vertical profile 2) before and during the 838 monitoring campaign, as well as water contents used for in situ parameter optimization

839 Fig. 6. Hydraulic parameter estimates and confidence intervals (95\%) from the in situ

840 data inversion for the four layers and all vertical profiles (Eq. (1) and (2), HYDRUS

841 software)

842 Fig. 7. Measured and simulated water content evolution in the VFCW at different

843 depths during the monitoring campaign (Simulation performed with hydraulic

844 parameters from in situ water content data inversion)

845 Fig. 8. Measured and simulated water contents with hydraulic parameters (left) from 846 direct laboratory methods and (right) from inverse laboratory method 
Author-produced version of the article published in Ecological Engineering (2013), vol. 60, p. 325-335

The original publication is available athttp://www.sciencedirect.com/ 10.1016/j.ecoleng.2013.06.042

847 Fig. 9. $K_{s}$ values for the four layers through the various optimizations 